\title{
The future of health care in the United Kingdom
}

\author{
Poor outlook for equity, comprehensiveness, and equality of access
}

Rationing and priority setting stay at the top of the health care agenda, with the publication this month of three major reports on the future of health care in the United Kingdom..$^{1-3}$ All three make clear that health service managers are no longer prepared to take sole responsibility for unpopular funding decisions. Instead they want the government to "concede publicly the inevitability of rationing." More revealingly, however, all three reports illustrate that senior NHS managers cannot reconcile the principles of the NHS with its continued underfunding.

The National Association of Health Authorities and Trusts' paper on the Future Direction of Health Care is a short discussion document which re-examines the principles of the NHS and discusses the organisation, delivery, and funding of health care in the United Kingdom. ${ }^{1}$ The Institute of Health Services Management's final report, Future Health Care Options, ${ }^{2}$ covers similar ground but in more depth, with the help of three briefing papers and two working papers. ${ }^{4-8}$ Its aim is to "restate the values on which health services are delivered and to open up the debate on rationing to the public arena in the UK." The third report, commissioned by management consultants Andersen Consulting and BursonMarsteller, is the outcome of a survey of European health policy makers "to identify and predict the strategies which will be employed throughout Europe to balance quality and access to health care with cost control." 39

The public and private health sector managers responsible for the Institute of Health Service Management's Future Health Care Options start promisingly by endorsing the key values of the 1948 NHS: equity, comprehensiveness, and equality of access. One might have expected them to introduce the rationing debate by exploring whether the internal market is the most effective way of upholding these principles. But both this and the two other reports show reluctance to tackle this issue. Given managers' role in implementing the internal market and the accompanying massive changeswhich "managers alone have driven and sustained"2-this is clearly not an easy route of inquiry for them to pursue.

By ignoring the effect of the internal market on the principles of the NHS, however, the institute's final report never properly opens up the rationing debate. Instead the report becomes a vehicle for current management frustrations. Underfunding is only one of these. As problematical is tight government control but without a clear strategy. The absence of clear national guidelines leaves managers having to set precedents, exposing them to criticism. For example, politicians' failure within the health strategy to balance health promotion against health care results in resource conflicts at local level. These are compounded by the need to reconcile conflicting national and local priorities. All these difficulties are beset by structural and organisation problems, including the lack of accountability of providers and general practitioner fundholders. Managers are also aware that apparent increases in efficiency (as measured by such insensitive, and often perverse, instruments as the purchasers' efficiency index) will not cure underfunding, guarantee comprehensive services, or even represent the best use of resources.

The solution to these frustrations held out by Future Health Care Options includes radical measures on funding and organisation and the substitution of regulation for line management. Their aim is to enable managers to be freer to manage and to escape central control. Proposals for future funding include social insurance and local taxation. Managers also want more freedom to involve the commercial sector in providing care and the dismantling of purchasing boundaries between social and health services.

Both these reports from UK health service management bodies suggest that managers want it all their own way. They want government to take unpleasant decisions on rationing, while leaving them free to manage, set funding levels, and enjoy greater flexibility to develop a market in health care. Moreover, the political implications of some of these changes, not least the need for some semblance of democratic process, receive no attention.

Developing the market in health care is also the thrust of the Andersen-Burson-Marsteller report. Using 180 questions they surveyed 10000 health policymakers in 10 European countries and then subjected the results to further analysis by a panel of experts within each country.

Management consultants are clearly not constrained by worries about study design since they describe an overall response rate of $27 \cdot 5 \%$ as excellent. Nor do they reveal how the sample was chosen and stratified or what the response rate was by country. The questions are not included in the report and we are presented with only a selection of the findings on which the UK panel (comprising mainly senior health sector managers and management policymakers) was asked to comment.

Unlike the first two reports, this report is not distracted by the issues of the internal market and makes no attempt to camouflage its conclusions with the rhetoric of equity, comprehensiveness, or equality of access. If its predictions are 
right it rings the death knell for the NHS and opens the way for unprecedented deregulation.

The good news for the commercial sector is that the panel predicts increased spending on private health care by both NHS purchasers and private insurers. The bad news for the public is that multitiered health care systems will emerge with different standards of care available to patient groups depending on their access to private care and ability to pay. The report recognises that this is already happening as a consequence of devolving purchasing to districts and fundholders.

The panel has a definite view of who the consumers are, but they are not poor, old, chronically sick, or disabled people. While the panel predicts increased choice, increased participation, and increased levels of services for patients it fails to relate these to the predictions made for the future of purchasers and providers. Thus while "patient levers" will force the general practitioner fundholder to offer all this increased choice they see "no problem with GPs having to be more selective about who they refer since they now have a budget to work to." Nor do they see a problem with the reduction in numbers of hospital beds: "Beds will just disappear; the hospital authorities won't consult anyone, they will just take them out of use." And hospitals will close as a result of cost containment, switches in contracts, and competition with the private sector.

These reports expose managers' growing discomfort with politicians and the role they are being asked to play in the continued underfunding of the health service. They also suggest that managers are concerned less with protecting the values and principles of the NHS than with protecting themselves from the wrath of politicians and the fallout from their local communities. The reports also show that the internal market has not controlled costs, provide further anecdotal evidence that it has harmed the central tenets of the NHS, and suggest how deregulation and alternative funding will accelerate these processes. If health service managers really want to get the debate on priority setting and rationing underway they should stop crystal ball gazing. What we need from them is an immediate and honest evaluation of the impact of the internal market on equity, comprehensiveness, and equality of access to health care for the people of Britain.

ALLYSON M POLLOCK

St George's Hospital Medical School Senior lecturer in public health medicin London SW 17 ORE

\footnotetext{
Ham C, Appleby J. The future direction of the NHS. Birmingham: National Association of Health Authorities and Trusts, 1993.

2 Institute of Health Service Management Policy Unit. Future health care options: final report. London IHSM, 1993.

3 Burson-Marsteller. The future of UK health care. London: Burson-Marsteller, 1993.

4 Ensor T. Future health care options: funding health care. London: IHSM, 1993.

5 Institute of Health Services Management Policy Unit. Future health care options: the organisation: a new direction for the NHS. London: IHSM, 1993.

6 Ham C, Tremblay M. Future health care options: Europe. London: IHSM, 1993.

7 Wall A. Future health care options: values and the NHS. London: IHSM, 1993.

8 Institute of Health Service Management Policy Unit. Future health care options: distribution of health care resources-decisions and choices. London: IHSM, 1993.

9 Burson-Marsteller. The future of European health care. London: Burson-Marsteller, 1993.
}

\section{Sex selection}

\section{"The rights of man" or the thin edge of a eugenic wedge?}

If the ability to choose the sex of one's children had been available 70 years ago some aspects of recent history might have been different. George VI and Councillor Roberts, for example, might not have chosen to father only girls, depriving us of the Queen and Lady Thatcher.

Two recent events have focused attention on the imminent reality of preconceptional sex selection. The first of these is the opening of a gender clinic in north London '; the second is the publication by the Human Fertilisation and Embryology Authority of a consultation document seeking views on whether primary sex selection should be freely available. ${ }^{2}$ Although methods of selecting sex before conception are not entirely reliable, it is timely to consider how we wish to respond to them when they become so.

Is primary sex selection (that is, selection of sex even when the fetus is not known to have a sex linked disorder) merely extending the control we already have over family size to include composition (for example, ensuring that a family ends up with "one of each")? Or is it fundamentally different, involving the selection of individuals on the basis of characteristics unrelated to illness?

The debate hinges on the likely consequences of the intervention for prospective parents, families, and society in general. A reliable test would present all prospective parents with choices: the choice of whether to take the test and, if they do, to choose the child's sex. How would such decisions be made and by whom: the mother, the father, other siblings, grandparents? If there was conflict about the choice would one parent feel less responsibility or love for the child?

In effect, parents will be invited to weigh up the relative merits of a male or a female child before conception.
Preferences vary among societies. While there is a preference for male children in some societies, such as those with dowry systems, it is weaker in Western societies. ${ }^{3} \mathrm{~A}$ recent American study of university students has shown that over the past 15 years the preference for male children has fallen. ${ }^{3}$ If the sampled students had had all the children they wanted, in $1972,55 \%$ of them would have been male, in contrast with $52 \%$ in 1987. Preferences for firstborns to be male fell from $85 \%$ to $70 \%$ over the same period. Despite this, of those using the first franchised clinics in America, Asia, and Europe, 236 couples have chosen to have boys while just 15 have chosen girls. ${ }^{1}$ In Britain most early consumers have been seeking male children (BMA conference on sex selection, London, April 1993).

The main demographic consequences that have been considered are a smaller population, as people are enabled to complete families with their preferred sex ratios, ${ }^{4}$ and changes in population sex ratios. Although amniocentesis and chorionic villus sampling have not altered sex ratios in Western countries, the use of these procedures is associated with an altered sex ratio in China and India in favour of male children. ${ }^{5}$ Sex selection offers the possibility of avoiding female infanticide and midtrimester abortions: while this seems attractive, a small but growing group in India argues that what is needed is an elimination of inequality, not of baby girls. ${ }^{6}$ What needs to change, it argues, is a set of social values that results in an obstetrician offering commiserations not congratulations on the birth of a healthy female child.

It is difficult to predict how people in Britain will respond once a reliable test is available. Responses will depend in part on the barriers to its use, such as cost and ease of access. 